\title{
PENGARUH CAPITAL ADEQUACY RATIO DAN RETURN ON EQUITY TERHADAP LOAN TO DEPOSIT RATIO PADA PT. BANK MANDIRI (PERSERO) TBK PERIODE 2011-2020
}

\author{
${ }^{1 *}$ Asep Muhammad Lutfi, ${ }^{2}$ Siti Julaiha \\ Universitas Pamulang, Tangerang Selatan, Banten, Indonesia \\ *dosen02469@unpam.ac.id
}

\begin{abstract}
Abstrak
Penelitian ini bertujuan untuk menganalisis Pengaruh Capital Adequacy Ratio (CAR) Dan Return On Equity (ROE) Terhadap Loan To Deposit Ratio (LDR) Pada PT. Bank Mandiri (Persero), Tbk. Penelitian ini menggunakan data laporan keuangan pada perusahaan yang terdaftar dalam Bursa Efek Indonesia periode tahun 2011-2020. Analisa data dilakukan dengan metode statistik deskriptif kuantitatif, uji asumsi klasik dan pengujian hipotesis dengan metode regresi linier berganda. Data diolah dan dianalisa dengan menggunakan program aplikasi SPSS vers 26. Hasil dari penelitian ini menunjukkan bahwa variabel Capital Adequacy Ratio (CAR) berpengaruh negatif dan signifikan terhadap Loan To Deposit Ratio (LDR) dengan hasil Thitung sebesar -2,979 dan nilai signifikan sebesar 0,021. Untuk variabel Return On Equity (ROE) tidak berpengaruh terhadap Loan To Deposit Ratio (LDR) dengan hasil Thitung sebesar -1,263 dan nilai signifikan sebesar 0,247. Dan selanjutnya secara simultan Capital Adequacy Ratio (CAR) Dan Return On Equity (ROE) berpengaruh positif dan signifikan yang terhitung menggunakan Loan To Deposit Ratio (LDR). hal ini dapat dilihat dari Fhitung sebesar 11.502 dan nilai signifikan sebesar 0,006 dengan hasil (R2) 0,767 atau 76,7\% dan sisanya 23,3\% dipengaruhi oleh lainnya.
\end{abstract}

Kata Kunci: Capital Adequacy Ratio (CAR), Return On Equity (ROE) Dan Loan To Deposit Ratio (LDR)

\section{Abstract}

This study aims to analyze the effect of Capital Adequacy Ratio (CAR) and Return On Equity (ROE) on Loan To Deposit Ratio (LDR) at PT. Bank Mandiri (Persero), Tbk. This study uses financial statement data for companies listed on the Indonesia Stock Exchange for the period 2011-2020. Data analysis was carried out using quantitative descriptive statistical methods, classical assumption tests and hypothesis testing using multiple linear regression methods. The data were processed and analyzed using the SPSS vers 26 application program. The results of this study indicate that the Capital Adequacy Ratio (CAR) variable has a negative and significant effect on the Loan To Deposit Ratio (LDR) with a Tcount of $-2,979$ and a significant value of 0.021. The Return On Equity (ROE) variable has no effect on the Loan To Deposit Ratio (LDR) with a Tcount of -1.263 and a significant value of 0.247. And then simultaneously Capital Adequacy Ratio (CAR) and Return On Equity (ROE) have a positive and significant effect which is calculated using the Loan To Deposit Ratio (LDR). this can be seen from the Fcount of 11.502 and significant 0.006 with the result (R2) 0.767 or $76.7 \%$ and the value of $23.3 \%$ is influenced by others.

Keyword: Health, Knowledge, Real Per Capita Expenditure And The Development Of Msme, Poverty, Unemployment

\section{PENDAHULUAN}

Masalah yang dihadapi oleh suatu negara adalah mencari kondisi yang ideal bagi masyarakatnya dan bagaimana merealisasikannya. Penelusuran model yang ideal ini disebut dengan pembangunan. Kajian tentang pembangunan ekonomi, mengalami beberapa perubahahan. Pada tahun 1950 pembangunan diartikan sebagai pertumbuhan ekonomi, sehingga persepsi ini melahirkan pemahaman akan perlunya tingkat pertumbuhan ekonomi yang tinggi. Oleh Karena itu suatu negara dikatakan berhasil melaksanakan pembangunan apabila pertumbuhan ekonomi masyarakat 
tinggi (Hasan \& Azis 2018, h.11).

Perubahan kedua terjadi pada akhir 1960 dan awal 1970, pembangunan ekonomi tidak lagi menitik beratkan pada pertumbuhan ekonomi yang tinggi, namun bagaimana mengurangi angka kemiskinan, ketimpangan dan pengangguran (Todaro \& Smith, h.16). Perubahan ketiga terjadi pada tahun 1970 sampai 1980, kajian ekonomi pembangunan difokuskan kepada keberagaman negara sedang berkembang (NSB) dan identifikasi faktor penyebab mengapa terjadi perbedaan tingkat kinerja ekonomi dari setiap negara. Studi mulai diarahkan pada kekhususan karakteristik suatu negara berdasarkan kondisi empirisnya dan penggunaan asumsi yang berbeda-beda di setiap NSB (Lincolin 2014, h.5). Pada tahun 1980 sampai dengan 1990 munculnya pemikiran neoliberal, dalam ekonomi ini menekankan peran yang menguntungkan dari pasar besar, perekonomian terbuka, dan privatisasi badan usaha milik negara yang tidak efisien (Todaro \& Smith 2003, h.135). Oleh karena beragamnya pemahaman tentang pembangunan, maka hal ini merupakan satu konsep yang rumit untuk didefinisikan dan diukur dibandingkan dengan pertumbuhan ekonomi semata. Oleh Karena itu, Todara \& Smith (2003, h.18) menyatakan bahwa pembangunan haruslah dipandang sebagai proses multidimensi yang melibatkan berbagai perubahan mendasar dalam struktur sosial, sikap masyarakat, dan lembaga nasional, serta percepatan dan pertumbuhan, pengurangan ketimpangan, dan penanggulangan kemiskinan.

Pembangunan ekonomi merupakan hal yang penting bagi suatu negara. Salah satu sasaran pembangunan ekonomi pada tahun 2020 adalah meningkatkan kesejahteraan ekonomi masyarakat secara berkesinambungan. Adapun indikator yang dipergunakan adalah target pertumbuhan produk domestik bruto (PDB) sebesar 5,1\% sampai dengan 5,6 \%. Namun pada kenyataannya pada tahun 2020, PDB mengalami penurunan yang diakibatkan oleh Covid 19. Pada triwulan III 2020, pertumbuhan ekonomi sebesar $-3,49 \%$.
Kebijakan yang telah dilakukan oleh pemerintah dalam rangka pemulihan ekonomi adalah memperkokoh reformasi struktural. Beberapa kebijakan yang akan ditempuh pemerintah adalah memperbaiki kualitas sumber daya manusia dan melanjutkan dukungan untuk pemberdayaan UMKM.

Teori Solow menyatakan bahwa pertumbuhan ekonomi selalu bersumber dari satu atau lebih dari tiga faktor kenaikan kuantitas dan kualitas tenaga kerja (melalui pertumbuhan jumlah penduduk dan perbaikan pendidikan), penambahan modal dan teknologi. Sedangkan salah satu alat untuk mengukur pembangunan kualitas dan kuantitas tenaga kerja adalah IPM (Todaro, 2003: 150). Simon Kuznet mendefinisikan pertumbuhan ekonomi suatu negara sebagai "kemampuan negara itu untuk menyediakan barang-barang ekonomi yang terus meningkat bagi penduduknya, pertumbuhan kemampuan ini berdasarkan pada kemajuan teknologi dan kelembagaan serta penyesuaian ideologi yang dibutuhkannya". Ada tiga faktor utama dalam pertumbuhan ekonomi dari setiap bangsa yaitu: akumulasi modal, pertumbuhan penduduk dan kemajuan teknologi (Todaro dan Smith 2012, h.104).

Berdasarkan latar belakang permasalahan diatas, maka penulis tertarik untuk melakukan penelitian lebih lanjut dengan judul "Pengaruh Komponen Ipm Dan Perkembangan Umkm Terhadap Pertumbuhan Ekonomi Serta Implikasinya Pada Kemiskinan Dan Pengangguran Provinsi Daerah Istimewa Yogyakarta (DIY)".

\section{TINJAUAN PUSTAKA}

\section{Ekonomi Pembangunan}

Menurut beberapa pakar yaitu Lewellen 1995, Larrain 1994, Kiely 1995, teori pembangunan dapat dikelompokkan ke dalam dua paradigma yaitu modernisasi dan ketergantungan (Tikson 2005, h.64). Di dalam paradigma modernisasi termasuk teori-teori makro tentang pertumbuhan ekonomi dan perubahan sosial, dan mikro tentang nilai-nilai individu yang 
menunjang proses perubahan tersebut. Sedangkan paradigma ketergantungan mencakup keterbelakangan (underdevelopment), ketergantungan (dependent development), dan sistem dunia (world system theory) (Digdowiseiso 2019, h.1). Berbeda dengan pengelompokkan di atas, Tikson (2005, h.65) dan (Digdowiseiso 2019, h.1) mengelompokkan pembangunan menjadi tiga paradigma yaitu modernisasi, kerterbelakangan, dan ketergantungan.

Modernisasi memiliki asumsi dasar yang menjadi pangkal hipotesisnya dalam menawarkan rekayasa pembangunan. Cara paling tepat menurut modernisasi adalah menghilangkan kemiskinan melalui ketersediaan modal untuk melakukan investasi (Fakih 2002, h.44). Digdowiseiso (2019, h.21) menjelaskan pemikiran klasik teori modernisasi yang dikemukakan oleh para ahli, yaitu:

a. Smelsen, tentang differensiensi struktural bahwa teori modernisasi akan selalu melibatkan diferensiensi struktural.

b. Rostow, mengatakan bahwa pembangunan ekonomi ada lima tahapan, dan yang dianggap sebagai tahapan paling kritis adalah tahap tinggal landas

c. Coleman, tentang pembangunan politik yang ber-keadilan, bahwa ketiga teori pembangunan mirip dengan pendekatan sosiologis.

d. Asumsi, tentang teoritis dan metodologi bahwa teori modernisasi juga memberikan rumusan kebijaksanaan pembangunan.

\section{Pertumbuhan Ekonomi}

Pertumbuhan ekonomi menurut Kuznet (Jhingan 2007, h.57) adalah kenaikan jangka panjang dalam kemampuan suatu negara untuk menyediakan semakin banyak jenis barang-barang ekonomi kepada penduduknya, kemampuan ini tumbuh sesuai dengan kemajuan teknologinya dan penyesuaian kelembagaan dan ideologis yang diperlukan. Sedangkan, Todaro (2008, h.55) mendefinisikan pertumbuhan ekonomi sebagai suatu proses yang mantap dimana kapasitas produksi dari suatu perekonomian meningkat sepanjang waktu untuk menghasilkan tingkat pendapatan nasional yang semakin besar.

Subandi (2014, h.15), pertumbuhan ekonomi diartikan sebagai kenaikan GDP/GNP tanpa memandang apakah kenaikan itu lebih besar atau lebih kecil dari pertumbuhan penduduk, atau apakah terjadi perubahan struktur ekonomi atau tidak.

\section{Kemiskinan}

Kotze (dalam Hikmat 2004, h.6) menyatakan bahwa masyarakat miskin memiliki kemampuan yang relatif baik untuk memperoleh sumber melalui kesempatan yang ada. Kendatipun bantuan luar kadang-kadang digunakan, tetapi tidak begitu saja dapat dipastikan sehingga masyarakat bergantung pada dukungan dari luar. Pendekatan pemberdayaan ini dianggap tidak berhasil karena tidak ada masyarakat yang dapat hidup dan berkembang bila terisolasi dari kelompok masyarakat lainnya. Pengisolasian ini menimbulkan sikap pasif, bahkan keadaan menjadi semakin miskin.

Kemiskinan memiliki konsep yang beragam. World Bank (Purwanto 2007, h.300) mendefinisikan kemiskinan dengan menggunakan kemampuan daya beli, yaitu US \$ 1 atau US \$ 2 Perkapita. Sementara itu, BPS (2003, h. 2) mendefinisikan kemiskinan adalah ketidakmampuan dalam memenuhi kebutuhan dasar. Dengan kata lain, kemiskinan dipandang sebagai ketidakmampuan sisi ekonomi untuk memenuhi kebutuhan makanan maupun non makan yang bersifat mendasar.

\section{Pengangguran}

Pengangguran adalah masalah makroekonomi secara langsung dan 
merupakan masalah yang paling berat yang akan menyebabkan penurunan standar kehidupan dan tekanan psikologis (Mankiw 2006, h.154). Menurut Rahardja dan Manurung (2004, h.329), pengangguran adalah orang yang mencari kerja masuk dalam kelompok penduduk yang disebut angkatan kerja. Berdasarkan kategori usia, angkatan kerja berusia 15 sampai dengan 64 tahun. Tetapi tidak semua orang yang berusia 15 sampai dengan 64 tahun dihitung sebagai angkatan kerja. Yang dihitung sebagai angkatan kerja adalah penduduk 15-64 tahun dan sedang mencari kerja sedangkan yang tidak mencari kerja mungkin saja sedang mengurus keluarga atau sekolah, tidak masuk angkatan kerja. Jadi tingkat pengangguran adalah persentase angkatan kerja yang tidak/belum mendapatkan pekerjaan.

\section{Indeks Pembangunan Manusia}

Salah satu alat untuk mengukur pembangunan kualitas dan kuantitas tenaga kerja adalah IPM (Todaro, 2003: 150). Konsep pembangunan manusia dikembangkan 40 tahun lalu. Pertama kali, pembangunan konsep muncul karena isu pembangunan ekonomi berkelanjutan dan keraguan tentang kecukupan dari pertumbuhan ekonomi (Bagolin dan Comin 2008, h.10). Titik tertinggi perdebatan konsep terkait pembangunan manusia terjadi setelah tahun 1990, ketika The United Nation Development Program (UNDP) mengeluarkan laporan IPM. Kelebihan dari perhitungan IPM yang dikembangkan oleh UNDP adalah terdiri atas multidimensional indeks, fokus pada kehidupan manusia dibandingkan tentang arti bertahan hidup, mudah di hitung, mudah diimplementasikan dan dipahami, ketersediaan data yang diperlukan, dapat mengekspresikan kemampuan. Dimensi yang digunakan UNDP adalah umur panjang dan hidup sehat, pengetahuan dan standar hidup layak.

$$
\text { Tahun 2015, BPS telah }
$$

menggunakan perhitungan IPM yang telah diperbaharui dengan mempertimbangkan ketersediaan data sampai tingkat kabupaten/kota. Dengan hal ini, angka IPM Indonesia hasil perhitungan BPS tidak dapat dibandingkan dengan angka IPM Indonesia yang dihitung UNDP. Tinggi rendahnya nilai IPM tidak terlepas dari program pembangunan yang dilakukan oleh pemerintah baik ditingkat pusat maupun di daerah. Dimensi untuk mengukur IPM di Indonesia adalah indeks kesehatan, indeks pendidikan, dan indeks pengeluaran.

\section{a. Indeks Kesehatan}

Berdasarkan Undang-Undang No. 36 tahun 2009 kesehatan adalah keadaan sehat, baik secara fisik, mental, spritual maupun sosial yang memungkinkan setiap orang untuk hidup produktif secara sosial dan ekonomis (UUD No.36 2009, h. 2).

Indikator yang dipergunakan untuk mengukur dimensi kesehatan adalah Angka harapan hidup waktu lahir (AHH). Priyadi (2011, h. 288) mengemukakan bahwa semakin panjang angka harapan hidup seseorang di suatu daerah maka menunjukkan adanya peningkatan kehidupan dan kesejahteraan bagi masyarakat di daerah tersebut. Peningkatan Angka Harapan Hidup di setiap tahunnya diharapkan akan meningkatkan kesejahteraan masyarakat. Dengan kesejahteraan yang semakin meningkat, maka tingkat kemiskinan diharapkan dapat berkurang.

\section{b. Indeks Pendidikan}

Indikator yang dipergunakan dalam mengukur dimensi pengetahuan adalah indeks pendidikan, dimana indeks pendidikan diukur melalui angka harapan lama sekolah, rata-rata lama sekolah (BPS 2017, h.18). Berikut ini adalah uraiannya:

\section{1) Harapan Lama Sekolah (HLS)}

Adapun formula penghitungan 
HLS adalah sebagai berikut:

$$
H L S_{\alpha}^{t}=\sum_{i=\alpha}^{t} \frac{E_{i}^{t}}{P_{i}^{t}}
$$

2) Formula yang dipergunakan adalah sebagai berikut:

$$
R L S=\sum_{i} \frac{f_{i} \times j i}{\sum_{i} f_{i}}
$$

Untuk memperoleh indeks pendidikan (IP), indeks angka harapan lama sekolah dan indeks rata-rata lama sekolah digabungkan menjadi satu, formula rumusnya:

\section{c. Indeks Pengeluaran}

$$
I P=\frac{I_{H L S}+I_{R L S}}{2}
$$

Pengertian

pengeluaran

perkapita, menurut BPS (2016, h.9) adalah biaya yang dikeluarkan untuk konsumsi anggota rumah tangga pada periode tertentu. Sedangkan, Halim (2012, h.47) mendefinisikan pengeluaran perkapita secara keseluruhan bagi anggota rumah tangga yang termasuk dalam satu rumah tangga yaitu dengan memakai pengertian pengeluaran konsumsi rumah tangga.

\section{Usaha Mikro, Kecil dan Menengah}

$$
\text { Usaha Mikro, Kecil dan }
$$
Menengah (UMKM) adalah unit usaha produktif yang berdiri sendiri yang dilakukan oleh perseorangan atau badan usaha di semua sektor ekonomi (Tambunan 2012, h.11). Selanjutnya Tambunan menambahkan bahwa di Indonesia, definisi UMKM diatur dalam Undang-Undang Republik Indonesia No.20 Tahun 2008 tentang UMKM (Tambunan 2009, 16).

\section{METODE}

Populasi dari penelitian ini adalah seluruh data variabel yang berhubungan dengan indeks kesehatan, indeks pendidikan, pengeluaran perkapita dan perkembangan UMKM terhadap pertumbuhan ekonomi serta implikasinya terhadap kemiskinan dan pengangguran yang berjumlah 5 kabupaten dengan periode 10 tahun sehingga populasi berjumlah 50. Sampel dalam penelitian ini menggunakan sampel jenuh yaitu teknik penentuan sampel dengan mengambil jumlah populasinya, maka jumlah sampel sebanyak 50. Data yang dipakai dalam penelitian ini, jika dilihat dari sifatnya adalah data kuantitatif yang berbentuk angka dan dapat diukur. Data yang digunakan dalam penelitian ini adalah data sekunder, yaitu data dalam bentuk tahunan yang telah disusun dan diterbitkan oleh pihak terkait. Data yang diperlukan dalam penelitian ini adalah data sekunder yang pengumpulannya berupa data time series selama 10 tahun yaitu dari tahun 2010 sampai dengan 2019 dengan 5 Kabupaten, sehingga berjumlah 50 .

\section{HASIL DAN PEMBAHASAN}

1. Hasil Analisis Data Panel (Model I) a. Hasil Estimasi Model Data Panel Model 1

Berdasarkan pengujian berpasangan terhadap ketiga model regresi data panel model 1 , dapat disimpulkan bahwa hasil uji Chow model data panel lebih baik adalah menggunakan data panel fixed effect dan hasil uji hausman model data panel juga menunjukkan yang lebih baik adalah menggunakan model data panel random effect dan uji langrangge multiplier (LM) model data panel yang lebih baik adalah random effect, maka uji hipotesis dalam penelitian ini lebih baik menggunakan model fixed effect, berikut kesimpulan uji model data panel: 
Tabel 1. Kesimpulan Pengujian Model Regresi Data Panel (Model I)

\begin{tabular}{|c|c|c|c|}
\hline No. & Metode & Pengujian & Hasil \\
\hline 1. & Chow-Test & Fixed vs Common & Fixed Effect \\
\hline 2. & Hausman Test & Random vs Fixed & Random Effect \\
\hline 3. & Lagrange Multiplier & Common vs Random & Common Effect \\
\hline
\end{tabular}

\section{b. Hasil Analisis Regresi Data Panel Model 1}

Berdasarkan hasil regresi data panel maka terbentuk persamaan sebagai berikut:

\section{$Y=206,6647-122,2814 X_{1}+$ $\mathbf{9 , 4 3 3 5 2 3} \mathrm{X}_{2}+\mathbf{3 , 5 2 8 1 1 3} \mathrm{X}_{3}+$ $0,011834 \mathrm{X}_{4}$}

Maka analisanya sebagai berikut:

1) Nilai konstanta sebesar 206,6647 memiliki arti secara perhitungan statistik apabila seluruh variabel cateris paribus bernilai 0 , maka nilai PDRB akan meningkat sebesar 206,6647 .

2) Nilai koefisien regresi $X_{1}=$ 122,2814 memiliki arti secara statistik bahwa peningkatan 1 unit variabel angka harapan hidup akan menurunkan nilai PDRB sebesar 122,2814.

3) Nilai koefisien regresi $X_{2}=$ 9,433523 memiliki arti secara statistic bahwa peningkatan 1 unit variabel rata-rata HLS dan RLS akan meningkatkan nilai PDRB sebesar 9,433523.

4) Nilai koefisien regresi $X_{3}=$ 3,528113 memiliki arti secara statistik bahwa peningkatan 1 unit variabel pengeluaran perkapita akan meningkatkan nilai PDRB sebesar 3,528113.

5) Nilai koefisien regresi $X_{4}=$ 0,011834 memiliki arti secara statistik bahwa peningkatan 1 unit variabel perkembangan UMKM akan meningkatkan nilai PDRB sebesar 0,011834.

\section{c. Hasil Uji Simultan (Uji F) Model 1}

Berdasarkan hasil model 1 dapat dilihat bahwa nilai $F_{\text {hitung }}$ sebesar 21,45025 dan $F_{\text {tabel }}$ sebesar 2,61. $\mathrm{F}_{\text {tabel }}$ didapat dari nilai pembilang $(\mathrm{k}$ -
1) sebesar $(4-1=3)$ dan penyebut/df $=(\mathrm{n}-\mathrm{k}), \mathrm{df}=(50-1=49)$ maka didapat $F_{\text {tabel }}$ sebesar 2,79. Sehingga dapat disimpulkan bahwa $F_{\text {hitung }}>$ $\mathrm{F}_{\text {tabel }}$ maka menolak hipotesis nol yang artinya variabel independen (angka harapan hidup, rata-rata HLS dan RLS, pengeluaran perkapita dan perkembangan UMKM) secara simultan berpengaruh terhadap PDRB.

\section{d. Hasil Uji Parsial (Uji t) Model 1}

Berdasarkan tabel di atas berikut hasil analisis uji $\mathrm{t}$ (parsial):

1) Pengaruh Angka Harapan Hidup Terhadap PDRB

Berdasarkan hasil nilai $t_{\text {tabel }}$ dengan $\alpha=5 \%, n=50$ dan $k=1$ maka df $=(n-k)$ adalah $\mathrm{df}=(50-1)=$ 49 , maka tabel $(0,05 ; 49)=2,00958$ sehingga didapat perbandingan yaitu $-t_{\text {hitung }}<-t_{\text {tabel }}-2,228539<-$ 2,00958. Kemudian nilai probabilitas pada variabel didapatkan nilai angka harapan hidup $=0,0321$, sedangkan standard probability 0,05 atau $5 \%$ sehingga didapatkan perbandingan nilai probability angka harapan hidup $=0,0321<$ 0,05, sehingga disimpulkan variabel indenpenden angka harapan hidup berpengaruh secara signifikan terhadap variabel PDRB.

2) Pengaruh Rata-Rata HLS Dan RLS Terhadap PDRB

Berdasarkan hasil nilai $t_{\text {tabel }}$ dengan $\mathrm{a}=5 \%, \mathrm{n}=50$ dan $\mathrm{k}=1$ maka $\mathrm{df}=(\mathrm{n}-\mathrm{k})$ adalah $\mathrm{df}=(50-1)=$ 49 , maka $t_{\text {tabel }}(0,05 ; 49)=2,00958$ sehingga didapat perbandingan yaitu $t_{\text {hitung }}>t_{\text {tabel }}$ 3,172598 > 2,00958. Kemudian nilai probabilitas pada variabel 
didapatkan nilai Rata-Rata HLS Dan RLS $=0,0029$, sedangkan standard probability 0,05 atau $5 \%$ sehingga didapatkan perbandingan nilai probability RataRata HLS Dan RLS = 0,0029 < 0,05, sehingga disimpulkan variabel indenpenden Rata-Rata HLS Dan RLS berpengaruh secara signifikan terhadap variabel PDRB.

3) Pengaruh Pengeluaran Perkapita terhadap PDRB

Berdasarkan hasil nilai $t_{\text {tabel }}$ dengan $a=5 \%, n=50$ dan $k=1$ maka df $=(n-k)$ adalah $\mathrm{df}=(50-1)=$ 49 , maka $t_{\text {tabel }}(0,05 ; 49)=2,00958$ sehingga didapat perbandingan yaitu $t_{\text {hitung }}<t_{\text {tabel }} 1,369054<$ 2,00958. Kemudian nilai probabilitas pada variabel didapatkan nilai Pengeluaran Perkapita $=0,1784$, sedangkan standard probability 0,05 atau $5 \%$ sehingga didapatkan perbandingan nilai probability Pengeluaran Perkapita $=0,1784>$ 0,05, sehingga disimpulkan variabel indenpenden Pengeluaran Perkapita tidak berpengaruh secara signifikan terhadap variabel PDRB.

4) Pengaruh Perkembangan UMKM terhadap PDRB

Berdasarkan hasil nilai $t_{\text {tabel }}$ dengan $a=5 \%, n=50$ dan $k=1$ maka df $=(n-k)$ adalah $\mathrm{df}=(50-1)=$ 49 , maka $t_{\text {tabel }}(0,05 ; 49)=2,00958$ sehingga didapat perbandingan yaitu $t_{\text {hitung }}<t_{\text {tabel }} 0,015195<$ 2,00958. Kemudian nilai probabilitas pada variabel didapatkan nilai perkembangan UMKM $=0,9879$, sedangkan standard probability 0,05 atau $5 \%$ sehingga didapatkan perbandingan nilai probability perkembangan $\mathrm{UMKM}=0,9879>$ 0,05, sehingga disimpulkan variabel indenpenden perkembangan UMKM tidak berpengaruh secara signifikan terhadap variabel PDRB.

\section{e. Hasil Koefisien Determinasi Model}

1

Berdasarkan hasil koefisien determinasi pada tabel di atas dapat dilihat bahwa nilai Adjusted $R^{2}$ adalah 0,769522 yang berarti kemampuan variabel independen yang digunakan dalam penelitian yaitu angka harapan hidup, rata-rata HLS dan RLS, pengeluaran perkapita dan perkembangan UMKM dalam menjelaskan variabel dependen (PDRB) sebesar 76,9522\% sisanya 23,0478\% dijelaskan oleh variabel lain yang tidak dimasukkan dalam model penelitian.

\section{Hasil Analisis Data Panel (Model 2)}

a. Hasil Estimasi Model Data Panel Model 2

Berdasarkan pengujian berpasangan terhadap ketiga model regresi data panel model 2, dapat disimpulkan bahwa hasil uji Chow model data panel lebih baik adalah menggunakan data panel fixed effect dan hasil uji hausman model data panel juga menunjukkan yang lebih baik adalah menggunakan model data panel random effect dan uji langrangge multiplier (LM) model data panel yang lebih baik adalah random effect, maka uji hipotesis dalam penelitian ini lebih baik menggunakan model fixed effect, berikut kesimpulan uji model data panel:

Tabel 2 Kesimpulan Pengujian Model Regresi Data Panel (Model 2)

\begin{tabular}{|c|c|c|c|}
\hline No. & Metode & Pengujian & Hasil \\
\hline 1. & Chow-Test & Fixed vs Common & Fixed Effect \\
\hline 2. & Hausman Test & Random vs Fixed & Random Effect \\
\hline 3. & Lagrange Multiplier & Common vs Random & Common Effect \\
\hline
\end{tabular}




\section{b. Hasil Analisis Regresi Data Panel Model 2}

Berdasarkan hasil regresi data panel maka terbentuk persamaan sebagai berikut:

\section{$Z_{1}=25,32665-2,459032 Y$}

Maka analisanya sebagai berikut:

1) Nilai konstanta sebesar 25,32665 memiliki arti secara perhitungan statistik apabila seluruh variabel PDRB cateris paribus bernilai 0, maka nilai kemiskinan akan meningkat sebesar 25,32665.

2) Nilai koefisien regresi $Y=$ 2,459032 memiliki arti secara statistik bahwa peningkatan 1 unit variabel PDRB akan menurunkan nilai kemiskinan sebesar 2,459032.

\section{c. Hasil Uji Parsial (Uji t) Model 2}

Berdasarkan hasil nilai $t_{\text {tabel }}$ dengan $\mathrm{a}=5 \%, \mathrm{n}=50$ dan $\mathrm{k}=1$ maka $\mathrm{df}=(\mathrm{n}-\mathrm{k})$ adalah $\mathrm{df}=(50-1)=49$, maka $t_{\text {tabel }}(0,05 ; 49)=2,00958$ sehingga didapat perbandingan yaitu $-t_{\text {hitung }}<-$ $t_{\text {tabel }}-3,202371<-2,00958$. Kemudian nilai probabilitas pada variabel didapatkan nilai PDRB $=0,0025$, sedangkan standard probability 0,05 atau $5 \%$ sehingga didapatkan perbandingan nilai probability PDRB = $0,0025<0,05$, sehingga disimpulkan variabel indenpenden PDRB berpengaruh secara signifikan terhadap variabel kemiskinan. d. Hasil Koefisien Determinasi Model 2

Berdasarkan hasil koefisien determinasi pada tabel di atas dapat dilihat bahwa nilai $R^{2}$ adalah 0,729768 yang berarti kemampuan variabel independen yang digunakan dalam penelitian yaitu PDRB dalam menjelaskan variabel dependen (kemiskinan) sebesar 72,9768\% sisanya 27,0232\% dijelaskan oleh variabel lain yang tidak dimasukkan dalam model penelitian.

\section{Hasil Analisis Data Panel (Model 3)}

a. Hasil Estimasi Model Data Panel Model 3

Berdasarkan pengujian berpasangan terhadap ketiga model regresi data panel model 3, dapat disimpulkan bahwa hasil uji Chow model data panel lebih baik adalah menggunakan data panel fixed effect dan hasil uji hausman model data panel juga menunjukkan yang lebih baik adalah menggunakan model data panel random effect dan uji langrangge multiplier (LM) model data panel yang lebih baik adalah random effect, maka uji hipotesis dalam penelitian ini lebih baik menggunakan model fixed effect, berikut kesimpulan uji model data panel:

Tabel 3 Kesimpulan Pengujian Model Regresi Data Panel (Model 3)

\begin{tabular}{|c|c|c|c|}
\hline No. & Metode & Pengujian & Hasil \\
\hline 1. & Chow-Test & Fixed vs Common & Fixed Effect \\
\hline 2. & Hausman Test & Random vs Fixed & Random Effect \\
\hline 3. & Lagrange Multiplier & Common vs Random & Common Effect \\
\hline
\end{tabular}

b. Hasil Analisis Regresi Data Panel Model 3

$\mathrm{Z}_{2}=\quad 13,56174-0,817554 \mathrm{Y}$

Maka analisanya sebagai berikut:

1) Nilai konstanta sebesar 13,56174 memiliki arti secara perhitungan statistik apabila seluruh variabel PDRB cateris paribus bernilai 0, maka nilai pengangguran akan meningkat sebesar 13,56174.
2) Nilai koefisien regresi $Y=$ 0,817554 memiliki arti secara statistik bahwa peningkatan 1 unit variabel PDRB akan menurunkan nilai pengangguran sebesar 0,817554.

c. Hasil Uji Parsial (Uji t) Model 3

Berdasarkan nilai $t_{\text {tabel }}$ dengan $a$ $=5 \%, \mathrm{n}=50$ dan $\mathrm{k}=1$ maka $\mathrm{df}=(\mathrm{n}-$ k) adalah $\mathrm{df}=(50-1)=49$, maka $t_{\text {tabel }}$ 
$(0,05 ; 49)=2,00958$ sehingga didapat perbandingan yaitu $-t_{\text {hitung }}<-t_{\text {tabel }}$ $3,028937<-2,00958$. Kemudian nilai probabilitas pada variabel didapatkan nilai PDRB $=0,0041$, sedangkan standard probability 0,05 atau $5 \%$ sehingga didapatkan perbandingan nilai probability PDRB $=0,0041<0,05$, sehingga disimpulkan variabel indenpenden PDRB berpengaruh secara signifikan terhadap variabel pengangguran.

d. Hasil Koefisien Determinasi Model 3

Berdasarkan hasil koefisien determinasi pada tabel di atas dapat dilihat bahwa nilai $R^{2}$ adalah 0,724275 yang berarti kemampuan variabel independen yang digunakan dalam penelitian yaitu PDRB dalam menjelaskan variabel dependen (pengangguran) sebesar $72,4275 \%$ sisanya $27,5725 \%$ dijelaskan oleh variabel lain yang tidak dimasukkan dalam model penelitian.

\section{PENUTUP}

\section{Kesimpulan}

Berdasarkan analisis pada bab IV maka kesimpulan penelitian ini adalah sebagai berikut:

a. Kesehatan, pengetahuan, pengeluaran perkapita riil, dan perkembangan UMKM memiliki pengaruh yang signifikan secara bersama-sama terhadap pertumbuhan ekonomi di Provinsi DIY.

b. Kesehatan memiliki pengaruh negatif yang signifikan terhadap pertumbuhan ekonomi di Provinsi DIY.

c. Pengetahuan memiliki pengaruh positif yang signifikan terhadap pertumbuhan ekonomi di Provinsi DIY.

d. Pengeluaran perkapita riil tidak memiliki pengaruh positif yang tidak signifikan terhadap pertumbuhan ekonomi di Provinsi DIY.

e. Perkembangan UMKM tidak memiliki pengaruh yang positif pertumbuhan ekonomi di Provinsi DIY.

f. Pertumbuhan ekonomi memiliki pengaruh negatif yang signifikan terhadap kemiskinan di Provinsi DIY.

g. Pertumbuhan ekonomi memiliki pengaruh negatif yang signifikan terhadap pengangguran di Provinsi DIY.

\section{Saran}

Berdasarkan kesimpulan yang telah diuraikan di atas, maka saran yang dapat penulis uraikan adalah sebagai berikut:

a. Kesehatan tidak memiliki pengaruh yang signifikan terhadap pertumbuhan ekonomi, namun pemerintah di harapkan dapat meningkatkan kualitas pelayanan kesehatan terhadap masyarakat di Provinsi DIY.

b. Pengetahuan di Provinsi DIY yang diukur melalui harapan lama sekolah dan rata-rata lama sekolah belum merata di setiap kabupaten, untuk itu perlu adanya strategi-strategi untuk meningkatkan pengetahuan di Provinsi DIY dengan cara meningkatkan pelayanan terhadap pendidikan dan melaksanakan peningkatan kualitas pendidikan untuk dapat menghasilkan masyarakat yang berpengetahuan luas dan terampil agar dapat menciptakan lapangan pekerjaan.

c. Standar hidup layak diukur melalui pengeluaran perkapita riil, untuk dapat meningkatkan pengeluaran perkapita riil masyarakat perlu adanya peningkatan pendapatan masyarakat, untuk itu perlu adanya perbaikan sistem pemberdayaan ekonomi bagi masyarakat, agar 
pengeluaran perkapita masyarakat meningkat. Pengeluaran perkapita berhubungan secara langsung dengan pendapatan masyarakat, pendapatan dapat meningkat jika sumber daya dari manusia baik. Oleh karena itu berbicara tentang peningkatan pengeluaran perkapita maka tidak dapat lepas dari peningkatan kualitas sumber daya manusianya.

d. Dalam upaya peningkatan perkembangan UMKM, pemerintah diharapkan dapat melakukan pendampingan dan bantuan modal terhadap UMKM yang berada di Provinsi DIY.

e. Dalam upaya menurunkan kemiskinan Provinisi DIY disarankan meningkatkan kualitas sumber daya manusia serta memeberikan pendampingan dan bantuan modal kepada pelaku UMKM.

f. Dalam upaya menurunkan pengangguran Provinisi DIY disarankan meningkatkan kualitas sumber daya manusia serta memberikan pendampingan dan bantuan modal kepada pelaku UMKM.

g. Bagi peneliti disarankan memperluas penelitian dengan menambah variabel penelitan yang dapat meningkatkan pertumbuhan ekonomi serta menurunkan angka kemiskinan dan pengangguran di Provinsi DIY.

\section{DAFTAR PUSTAKA}

Bagolin, I. P. 2008. Human Development Index (HDI) and its family of indexes: an evolving ctritical review. Revista de Economia. 34(2). 7-28.

Benis, A. R. 2014. The impact of small and medium-sized entrepreneur on economic growth in iran. Global journal of management and business research. 14(2) 58-65.

BPS Indonesia. 2003. Data dan Informasi Kemiskinan Tahun 2003. Jakarta : Badan Pusat Statistik.
2008. Pedoman Praktis Perhitungan PDRB Kabupaten/Kota . Jakarta : Badan Pusat Statistik.

Badan Pusat Statistik Provinsi Banten. 2016. Pengeluaran dan Konsumsi Rumah Tangga Provinsi Banten. Banten: Badan Pusat Statistik Provinsi Banten.

.2019. Indeks Pembangunan Manusia . Jakarta : BPS

Chalid, N. 2010. Pengeluaran Konsumsi Rumah Tangga di Daerah Riau. Jurnal Ekonomi. 18(1). 28-40.

Dewi, N. L. S., \& Sutrisna, I. K. 2014. Pengaruh komponen indeks pembangunan manusia pertumbuhan ekonomi Provinsi Bali. E-Jurnal EP UNUD. 3(3). 106-114.

Digdowiseiso, K. 2019. Teori Pembangunan. Jakarta: Lembaga PenerbitanUniversitas Nasinal.

Dowling, J. M., \& Valenzuela, R. 2010. Economic Development in Asia, second edition. Singapura: CENGAGE Learning.

Ekosiswoyo, R et all. 2008. Strategi Akselerasi Pencapaian IPM Bidang Pendidikan Untuk Mendukung Kebijaksanaan Pembangunan Jangka Menengah Kota Semarang. Riptek. 1(2). 23-33.

Elistia., \& Syahzuni, B.A. 2018. The Correlation of The Human Development towards economic growth (GDP per capita) in 10 ASEAN member country. Journal of humanity and social studies. 02(02). 40-46.

Fakih, M. 2002. Runtuhnya Teori Pembangunan dan Globalisasi. Yogyakarta: Pustaka Belajar.

Gherghina, S. C et all. 2020. Small and Medium Sized enterprises (SMEs) : the engine of economic through investments and innovation. Suistanbility.2020(12). 1-22.

Halim, M. A. 2012. Teori Ekonomika Edisi 1. Tangerang : Jelajah Nusa.

Hasan, M., \& Aziz, M. 2018. Pembangunan Ekonomi dan Pemberdayaan Masyarakat : Strategi Pembangunan Manusia Dalam Persfektif Ekonomi Lokal. Makasar : CV Nur Lina

Hikmat, H. 2004. Strategi Pemberdayaan Masyarakat. Bandung : Penerbit Humaniora. 
Iskandar, I. 2017. Effect of human development index fund on economic growth through a special autonomy. Jurnal Ekonomi Pembangunan. 18(1). 4049.

Jhingan, 2007. Ekonomi Pembangunan dan Perencanaan ed.3. Jakarta : Rajawali Press

Keskin, $\mathrm{H}$ et all. 2010. The Importance of SMES in Developing Economies. 2nd International Symposium on Suistainable Development. June 8-9 2010, Sarajevo. 183-192.

Kusumaningrum, R. S. D. 2013. Link Of Fiscal Decentralization To Poverty Reduction: Indonesian Context. Jurnal Economia. 9(2). 116-129.

Lincolin, A. 2009. Pengantar Perencanaan Ekonomi Daerah. Yogyakarta : BPFE. 2010. Ekonomi Pembangunan. Yogyakarta : Unit Penerbit dan Percetakan STIM YKPN Yogyakarta. 2014. Ekonomi Pembangunan Lanjutan. Tangerang : Universitas Terbuka-Kementerian Pendidikan dan Budaya.

Lutfi, A. M., et al. (2021). Pengaruh Capital Adequacy Ratio Dan Bopo Ratio Terhadap Return On Asset Pada PT. Bank Muamalat Indonesia, Tbk Periode 2010-2019. Jurnal Ekonomi Efektif, 3(3), 420-428.

Mahadiansar et all. 2020. Paradigma Pengembangan Model Pembangunan Nasional. Jurnal Ilmu Administrasi. 17(1). 77-92.

Mankiw. 2007. Principle Of Economics. Jakarta : Salemba.

Martinez, J., \& Vazquez. 2011. The Impact of Fiscal Decentralizatyion. Filipina : Asian Development Bank.

Mujahid, N., \& Noman, M. 2019. The impact of SMES in the Economic development of Pakistan. SSRN Electronic Journal. 13(3). 1-13.

Nurlaili, R. U., \& Cahyadin, M. 2019. Economic And Non Economic Factors Effect Per Capita Income In Indonesia. Economics Development Analysis Journl. 8(4). 315-323.

Norton, S. W. 2002. Economic Growth and Poverty: In Search Of Trickle Down. Cato Jurnal. 22(2). 263-275.
Pasichnyi, M et all. 2019. The Impact of Fiscal Decentralization on Economic Development. Instrument Management and Financial Innovation. 16(3). 29-39.

Prishardoyo, B. 2008. Analisis Tingkat Pertumbuhan Ekonomi dan Potensi Ekonomi Terhadap Produk Domestik Regional Bruto (PDRB) Kabupaten Pati Tahun 2000-2005. Jejak. 1(1). 1-9.

Saputra, B., \& Mahmudi. 2012. Pengaruh Desentralisasi Fiskal Terhadap Ekonomi Dan Kesejahteraan Masyarakat. JAAI. 16(2). 185-199.

Subandi. 2014. Ekonomi Pembangunan. Bandung : Alfabeta.

Sukirno, S. 2015. Ekonomi Pembangunan Proses, Masalah dan Dasar Kebijakan. Jakarta : Kencana.

Tarigan, R. 2005. Ekonomi Regional : Teori dan Aplikasi. Jakarta: Bumi Aksara.

Tristanto, A., \& Diartho, H. C. 2018. Strategi Sektor Kesehatan Dalam Meningkatkan Indeks Pembangunan Manusia di Kabupaten Situbondo. WIGA Jurnal Penelitian Ilmu Ekonomi. 8(2). 1-9.

Todaro, M. P., \& Smith, S. C. 2003. Pembangunan Ekonomi. Jakarta: Erlangga.

2008.

Pembangunan Ekonomi. Ed.4. Jakarta : Erlangga.

Development(11

2012. Economic Addison Wesley. ed.).Singapore:

Undang-Undang Republik Indonesia Nomor 23 Tahun 2014. 2 Oktober 2014. Lembaran Negara Republik Indonesia Tahun 2014 Nomor 244. Jakarta.

Wirasasmita, Y, 2008. Uji Kelayakan Model. Bandung : Fakultas Ekonomi Universitas Padjajaran. 